\title{
Placas redondeadlas eritematovioláceas en el dorso de las manos
}

\section{Rounded purple erythematous plates on back of hands}

\author{
Yolanda Luján Giménez ${ }^{1}$, María Clara Mancinelli² ${ }^{2}$ Hernán Agustín Feola ${ }^{3}$ y María Alejandra Verea ${ }^{4}$
}

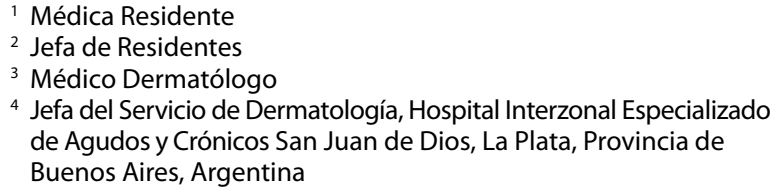

4 Jefa del Servicio de Dermatología, Hospital Interzonal Especializado de Agudos y Crónicos San Juan de Dios, La Plata, Provincia de Buenos Aires, Argentina

Contacto del autor: Yolanda Luján Giménez

E-mail: yolandalujangimenez@gmail.com

Fecha de trabajo recibido: 9/5/2020

Fecha de trabajo aceptado: 18/3/2021

Conflicto de interés: los autores declaran que no existe conflicto de interés.

Dermatol. Argent. 2021, 27 (1): 39-40

\section{CASO CLINICO}

Un paciente de 58 años, oriundo del Paraguay, con antecedentes personales de hipertensión arterial, accidente cerebrovascular sin secuelas y tabaquismo (exfumador de 15 cigarrillos por día durante 30 años), consultó por una dermatosis dolorosa en el dorso de ambas manos y en el codo izquierdo, de 7 días de evolución. Se encontraba en estudio por padecer un cuadro de meses de evolución, caracterizado por diarrea crónica, pérdida ponderal de $25 \mathrm{~kg}$, artralgias en las rodillas y episodios febriles.

En el examen presentaba, en áreas señaladas, múltiples placas redondeadas eritematovioláceas, de límites definidos, de 2 a $3 \mathrm{~cm}$ de diámetro.

Sobre las placas se asentaban vesículas y ampollas, algunas de contenido purulento, acompañadas de costras serohemáticas. Se observaba, además, edema con predominio en la mano derecha (Fotos 1 y 2 ).

En la biopsia de la piel se encontró una epidermis con acantosis y, en la dermis superficial, un infiltrado inflamatorio de predominio neutrofílico, con vasocongestión. No se observó vasculitis (Foto 3). Los cultivos y tinciones específicos para bacterias, micobacterias y hongos fueron negativos.

Los análisis de sangre revelaron anemia (hemoglobina $8,4 \mathrm{~g} / \mathrm{dl}$ y hematocrito de $25 \%$ ), leucocitosis con neutrofilia

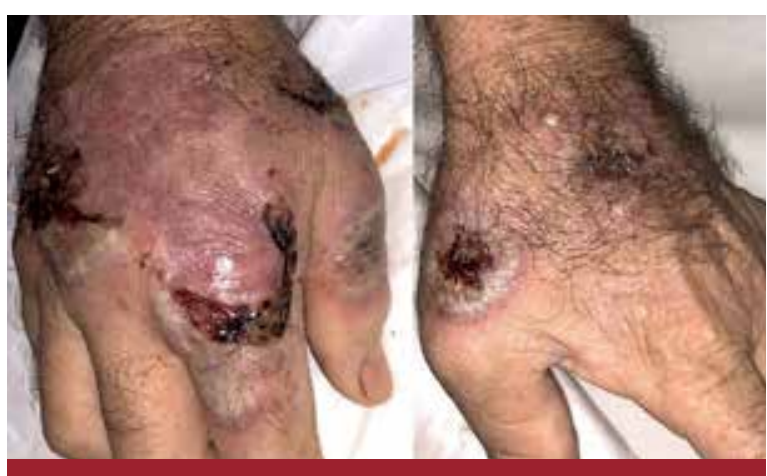

FOTO 1: Dorso de ambas manos con múltiples placas redondeadas, de límites definidos, eritematovioláceas, sobre las que asientan vesículas y ampollas, algunas de contenido purulento. de $76 \%$ y eosinofilia del $10 \%$, proteína C-reactiva $12 \mathrm{mg} / \mathrm{dl}$, velocidad de sedimentación globular $85 \mathrm{~mm} / \mathrm{h}$ e inmunidad por infección natural al virus de la hepatitis B (antígeno de superficie no reactivo, anticuerpo antiantígeno de superficie y anticuerpo anticore total reactivos).

No se detectaron anomalías en el resto de las pruebas de bioquímica en la sangre, el nivel de hormonas tiroideas ni los anticuerpos antinucleares. Tampoco en la radiografía ni en

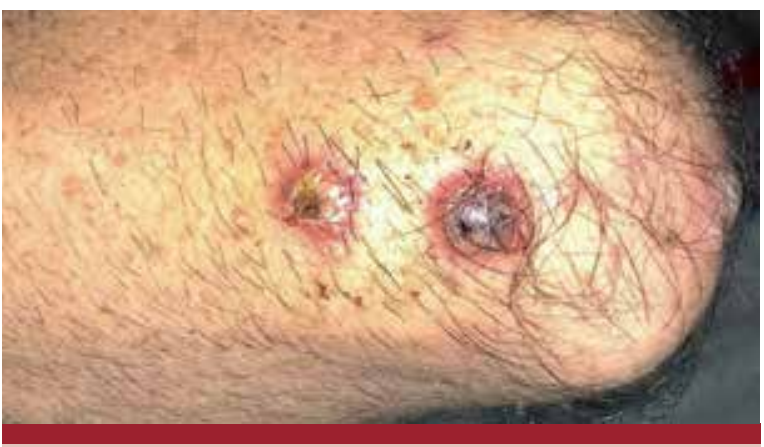

FOTO 2: Placas redondeadas de bordes definidos, eritematovioláceas, en el codo izquierdo.

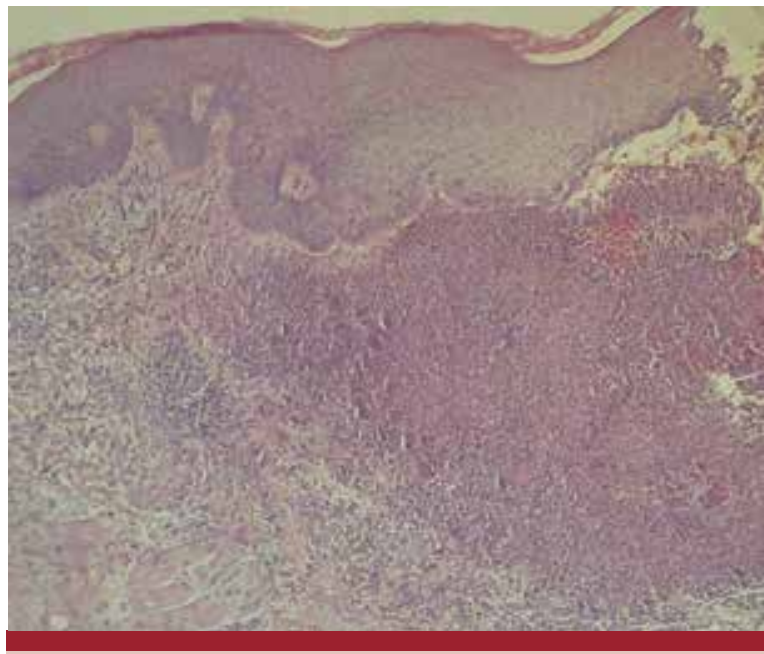

F0T0 3: Epidermis con espongiosis e hiperqueratosis difusa. En la dermis superficial, abundante acúmulo de polimorfonucleares, sin vasculitis (HyE, 10X). 
la tomografía computada de tórax. Las pruebas serológicas para el virus de la inmunodeficiencia humana y el virus de la hepatitis $\mathrm{C}$, los hemocultivos, el coproparasitológico seriado y el coprocultivo fueron negativos.

A través de los hallazgos endoscópicos e histopatológicos de mucosa intestinal típicos se arribó al diagnóstico de colitis ulcerosa.

\section{DIAGNÓSTICO}

Dermatosis neutrofilica del dorso de las manos (DNDM).

\section{EVOLUCIÓN}

Se indicó tratamiento sistémico con metilprednisona $40 \mathrm{mg} /$ día, mesalazina 3,6 g/día, tramadol $50 \mathrm{mg} /$ día y paracetamol $1 \mathrm{~g} /$ día, todos por vía oral.

Al cuarto día de tratamiento, presentó una evidente mejoría clínica de la dermatosis. Continuó con meprednisona en pauta descendente cada 5 días durante 2 meses.

\section{COMENTARIOS}

La DNDM es una enfermedad poco frecuente que ha sufrido modificaciones en su nomenclatura a través del tiempo.

En 1964, Douglas Robert Sweet describió por primera vez la dermatosis neutrofílica febril aguda, la cual se conoció rápidamente como "síndrome de Sweet". En 1983, Jorizzo et ál. introdujeron el término vasculitis pustular para describir un grupo de afecciones que exhibían cambios histológicos superpuestos del síndrome de Sweet y vasculitis leucocitoclástica. Strutton et ál., en 1995, publicaron los casos de 6 pacientes con lesiones simétricas en ambas manos y denominaron este cuadro vasculitis pustulosa de las manos. Clínicamente, estas lesiones se parecían al síndrome de Sweet, pero en la anatomía patológica mostraban una vasculitis leucocitoclástica prominente. Este hallazgo luego se consideró un epifenómeno secundario al proceso inflamatorio ${ }^{2-4}$.

En el año 2000, Galaria et ál. acuñaron el término dermatosis neutrofílica del dorso de las manos, después de describir 3 casos similares a los previos, pero sin vasculitis. Cuatro años más tarde, Weenig et ál. excluyeron la palabra "dorsal" porque observaron que varios pacientes también presentan lesiones en las palmas y en las regiones laterales

\section{BIBLIOGRAFÍA}

1. Sweet RB. An acute febrile neutrophtlic dermatosis. Br J Dermatol 1964:76:349-356.

2. Jorizzo JL. Pustular vasculitis: An emerging disease concept. J Am Acad Dermatol 1983;9:160-162.

3. Strutton $G$, Weedon D, Robertson I. Pustular vasculitis of the hands. JAm Acad Dermatol 1995;32:192-198.

4. Cohen PR. Skin lesions of Sweet syndrome and its dorsal hand variant contain vasculitis: an oxymoron or an epiphenomenon? Arch Dermatol 2002;138:400-403.

5. Galaria NA, Junkins-Hopkins JM, Kligman D, JamesWD. Neutrophilic dermatosis of the dorsal hands: Pustular vasculitis revisited. J Am Acad Dermatol 2000;43(5):870-874.

6. Weenig RH, Bruce AJ, McEvoy M, Gibson LE, et ál. Neutrophilic dermatosis of the hands: four new cases and review of the literature. de las manos y propusieron definir estos cuadros como "dermatosis neutrofílica de las manos". Hace poco, encontramos la denominación de síndrome de Sweet acral para cuadros clínicos semejantes ${ }^{5-7}$.

En una reciente revisión de 123 pacientes, se observó un leve predominio femenino, con una media de edad correspondiente a 62,1 años. Las asociaciones más importantes de la DNDM fueron alteraciones hematológicas (gammapatías, mielodisplasias o neoplasias), infecciones recientes (las más comunes fueron las infecciones respiratorias), tumores de órganos sólidos y enfermedad inflamatoria intestinal ${ }^{8}$.

La DNDM se presenta clínicamente como placas eritematovioláceas sobre las que se desarrollan pústulas y vesículas, que luego progresan a placas ulceradas dolorosas. Las lesiones suelen limitarse al dorso de las manos, con marcada predilección por el aspecto radial, específicamente, el área entre el pulgar y el dedo índice. También se las describió en las palmas con extensión hacia los antebrazos. Suelen acompañarse de fiebre, artralgias y malestar general. En la histopatología, puede observarse un infiltrado aséptico de neutrófilos polimorfonucleares en la dermis. Con menor asiduidad, se halló un infiltrado linfocítico predominante ${ }^{9-10}$.

El diagnóstico diferencial histológico de la DNDM incluye las infecciones agudas de la piel, el pioderma gangrenoso (que a menudo es histológicamente idéntico), el síndrome de artritis-dermatitis, la dermatosis neutrofilica reumatoide y el eritema elevatum et diutinum (casi siempre asociado a necrosis fibrinoide).

La terapia con corticosteroides se considera el tratamiento de primera línea para el DNDM. La mayoría de los pacientes requieren terapia sistémica para el control de la enfermedad. Sin embargo, los que presentan pocas lesiones cutáneas localizadas y sin síntomas sistémicos pueden responder bien a la terapia con corticosteroides locales. La colchicina, la dapsona y el yoduro de potasio se utilizan con menor frecuencia que los glucocorticoides sistémicos ${ }^{10}$.

Consideramos la DNDM una variante localizada del síndrome de Sweet. Es posible que su incidencia se encuentre subestimada debido a la dificultad para clasificarla como tal. El diagnóstico certero conduce a la búsqueda de enfermedades asociadas y evita retrasos en el inicio del tratamiento.

Int J Dermatol 2004;43:95-102.

7. Boussofara L, Gammoudi R, Ghariani N, Aounallah A, et ál. Dermatose neutrophilique des mains: un syndrome de Sweet acral? Rev Med Intern 2015;36:287-290.

8. Micallef D, Bonnici M, Pisani D, Boffa MJ. Neutrophilic dermatosis of the dorsal hands: a review of 123 cases. J Am Acad Dermatol 2019:S0190-9622.

9. Villa R, Torres Cortijo A, Ciancio R, Peláez O. Dermatosis neutrofílica (vasculitis pustular) del dorso de las manos. Dermatol Argen 2004;10:278-281.

10. Del Pozo J, Sacristán F, Martínez W, Paradela S, et ál. Neutrophilic dermatosis of the hands: presentation of eight cases and review of the literature. J Dermatol 2007;34:243-247. 